\title{
Assessing the capability of multi-scale drought datasets to quantify drought severity and to identify drought impacts: an example in the Ebro Basin
}

\author{
Enrique Morán-Tejeda, ${ }^{\text {a* Andrej Ceglar, }}{ }^{\mathrm{b}}$ Barbara Medved-Cvikl, ${ }^{\mathrm{b}}$ Sergio M. Vicente-Serrano, ${ }^{\mathrm{a}}$ \\ Juan I. López-Moreno, ${ }^{\mathrm{a}}$ José C. González-Hidalgo, ${ }^{\mathrm{c}}$ Jesús Revuelto, ${ }^{\mathrm{a}}$ Jorge Lorenzo-Lacruz, ${ }^{\mathrm{a}}$ \\ Julio Camarero ${ }^{\mathrm{d}}$ and Edmond Pasho ${ }^{\mathrm{a}}$ \\ ${ }^{a}$ Department of Geoenvironmental Processes and Global Change, Instituto Pirenaico de Ecología, CSIC, Zaragoza, Spain \\ b Biotechnical Faculty, University of Ljubljana, Ljubljana, Slovenia \\ c Departamento de Geografía, Universidad de Zaragoza, Zaragoza, Spain \\ d ARAID-Instituto Pirenaico de Ecología, CSIC, Zaragoza, Spain
}

\begin{abstract}
Assessing the risk, the severity and the likely evolution of droughts are key tasks for improving preparedness of regions prone to drought conditions, and mitigation of drought consequences. The access to real-time and high-quality climatic information is essential for this purpose. Different climatic databases are being developed and made available on real time by climatic research institutions, but their capability for quantifying droughts characteristics including severity, or spatio-temporal variability, is uncertain given their low spatial resolution. In this study, we assessed the capability of three databases with contrasted spatial resolution for measuring spatial and temporal variability of drought occurrence. The standardized precipitation index, calculated for each database, showed that the low resolution datasets allow an acceptable measurement of the magnitude, intensity and duration of droughts, while failing mostly in detecting the spatial patterns of the specific drought episodes. Moreover, the capability of the datasets for assessing the impacts of droughts on surface hydrology and tree growth was examined. Results confirmed the usefulness of the drought index for assessing drought impacts on water resources and forest ecosystems even when low resolution databases are used. Copyright (C) 2012 Royal Meteorological Society
\end{abstract}

KEY WORDS drought; real-time monitoring; standardized precipitation index; low resolution datasets; streamflow; water resources; dendrochronology; tree growth

Received 16 December 2011; Revised 20 June 2012; Accepted 23 June 2012

\section{Introduction}

Understanding, monitoring and mitigating droughts is a very difficult task as a consequence of the intrinsic nature of the phenomenon. A drought can be identified by its effects at different levels, but there is not a physical measurable variable that enables quantifying droughts. Due to its long-term development and duration, progressive character of its impacts and diffuse spatial limits, drought is amongst the most complex natural hazards to be identified, analysed, monitored and managed (Burton et al., 1978; Wilhite, 1993). Drought conditions are much more difficult to identify than other natural hazards since drought is commonly the result of a number of factors, which are only apparent after a long period of precipitation deficit. Moreover, it is very difficult to determine its onset, extent and end. In contrast to other natural hazards such as floods, which are typically restricted to small regions and to well-defined temporal intervals, drought is * Correspondence to: E. Morán-Tejeda, Instituto Pirenaico de Ecología,
CSIC, Zaragoza, Spain. E-mail: emoran@usal.es difficult to locate in time and space, affecting wide areas over long time periods.

As a consequence, most of the actions conducted to mitigate the negative effects of droughts are taken during the response and recovery phases of the disaster management cycle, i.e. they are focused on alleviating the immediate effects of drought once the phenomenon has occurred and restoring the affected areas to their previous state (Wilhite and Svoboda, 2000). While these measures are still necessary, their effectiveness is limited in the long-term basis, since they can only cope with specific catastrophes; i.e. they hardly contribute to reduce the vulnerability of the affected societies to drought. To reduce the drought vulnerability of the affected societies, it is necessary to promote an integral conception of drought risk management (Wilhite, 1996). Hence, eventoriented actions need to be complemented by other measures focused on promoting drought risk mitigation and preparedness (Wilhite, 2002).

Two fundamental requisites for reinforcing drought mitigation and preparedness in the long term are (1) an accurate drought risk assessment quantifying the extent of 
the hazard and the degree of vulnerability of the different regions; and (2) real-time information on the development of drought conditions and early forecasting of the likely evolution of the drought. This was acknowledged by the World Summit on Sustainable development $(24$ August to 2 September 2002) by the UN and the Johannesburg Plan of Implementation of the Agenda 21, who pointed to prioritize policy actions that include '... Providing affordable local access to information to improve monitoring and early warning related to desertification and drought.' The Review of implementation of Agenda 21 and the Johannesburg Plan of Implementation by the Commission on Sustainable Development of the UN Economic and Social Council (5-16 May 2008) stressed as well that 'the establishment and effective operation of systems and networks for drought monitoring, early warning and drought impact assessment are essential to the identification and formulation of effective and timely response actions'.

New technologies are available for developing monitoring and early warning systems based on real-time information to support decision making (Svoboda et al., 2002; Carbone et al., 2008). Currently, the main problem associated to the different drought monitoring systems developed worldwide is the access to high-quality climate information on a real time. In Europe, for example, the competences for collecting information correspond to the different states and governmental agencies, thus a common network of meteorological observatories is not available at the continental scale. In addition, most of the existing meteorological information is not openaccess and available on real time. One of the other major problems associated to climatic data is the existence of data gaps in the series, and the irregular spatial coverage of the meteorological stations. This is particularly relevant for precipitation, given its stochastic nature in time and space. To overcome these problems, it has become more and more frequent during the last two decades the development and use of gridded climatic databases (Trenberth, 1997; Goddard et al., 2001; Perry and Hollis, 2005; Herrera et al., 2012). These allow characterizing continuously in space the behaviour of climatic variables, thus permitting regional and supra-regional climatic studies being accomplished. However, they are product of statistical and geostatistical interpolations, and subject of a number of errors and uncertainties throughout the process of construction (Haylock et al., 2008). It should be recommendable, prior the use a gridded product, the correction of errors and the validation with other grids or with stations data (Hofstra et al., 2010; Herrera et al., 2012).

Nowadays, there are available different grid climatic databases that enables large-scale monitoring of climate variables, including those of the climate research unit (CRU, University of East Anglia) (Mitchell and Jones, 2005), the Telecommunication Net of the World Meteorological Organization (http://www.wmo.int/pages/prog/ www/index_en.html) or the Global Precipitation Climatology Centre (GPCC) (ftp://ftp-anon.dwd.de/pub/data/ gpcc/html/monitoring_download.html), among others. These climatic datasets have, however, very low spatial resolution (typically $100 \mathrm{~km}^{2}$ ), and do not enable to find spatial particularities in climate behavior, as the available station-based datasets by the national governmental agencies do. We thus consider essential to validate these datasets against finer resolution grids prior to their utilization for real-time monitoring of droughts in the different territories of the European continent.

The objectives of this paper are (1) to analyse the capability of 'low resolution' datasets for quantifying drought severity in a drought-prone area of southern Europe, the Ebro Basin (Northeast Spain); and (2) to assess the potential of the datasets for quantifying drought impacts on different sub-systems, such as hydrology and forestry. The assessment is based on the comparison of the standardized precipitation index (SPI) calculated from three different datasets of contrasted resolution. Details of each database will be given in Section 3.1.

\section{Study area}

The Ebro Basin (Figure 1) is located in the northeast of Spain and it is a region with complex topography and diverse climate conditions. In the North, the Pyrenees record a humid climate with precipitation above $1300 \mathrm{~mm}$. However, the centre of the Ebro Basin is the northernmost semi-arid region of Europe, water availability is often scarce and the management of water resources is a priority task. The Ebro valley is usually isolated from humid air masses by mountains located at the north and south, thus drought is a very frequent hazard in this area (Vicente-Serrano, 2005), affecting reservoir storage levels (Vicente-Serrano and López-Moreno, 2005), river flows (López-Moreno et al., 2011), crop production (Vicente-Serrano et al., 2006), and vegetation activity (Vicente-Serrano, 2007). Aridity is inherent to this area, with a negative water balance (precipitation minus evapotranspiration) as a consequence of the high potential evapotranspiration (PET) that occurs in summer. Thus, annual PET reaches $1300 \mathrm{~mm}$ in some sectors of the valley where annual precipitation hardly reaches $300 \mathrm{~mm}$. In spite of this, irrigation is a common practice in the low sectors of the Basin, and numerous reservoirs were built in the last decades to satisfy growing water demands. Drought monitoring is therefore a priority in the region. Real-time information on the developing of drought is necessary to assess the possible impacts on the ecology, water resources and cultivations of the Basin.

\section{Data}

\subsection{Precipitation datasets}

Three different precipitation datasets have been used for the purpose of the study.

- EBRO: a high quality and dense dataset of precipitation observations from the complete net of meteorological observatories available in Spain has been used as 

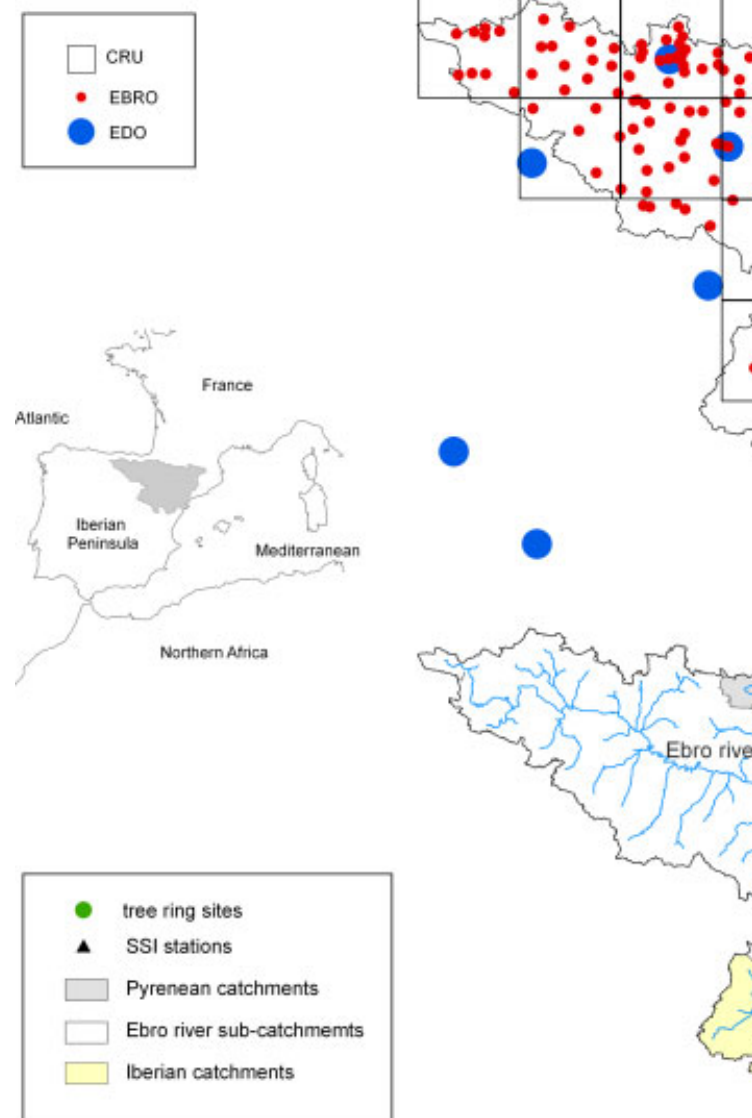

0 $50 \quad 100 \mathrm{~km}$
EBRO BASIN
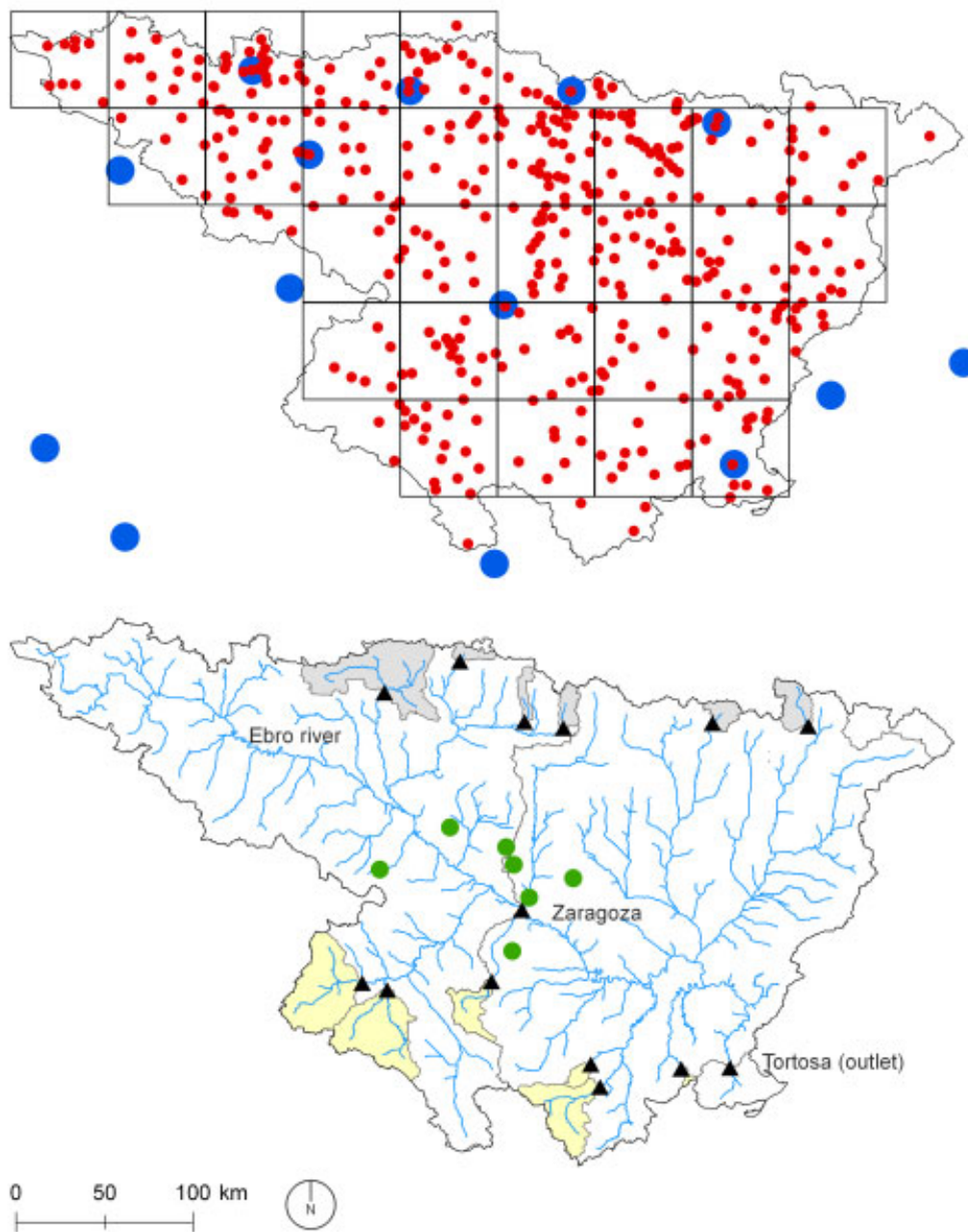

Figure 1. Spatial distribution of the stations used in the EBRO, EDO and CRU climatic datasets (upper map) and location of tree-ring sites and gauging stations analysed (bottom map).

the reference EBRO dataset (hereafter EBRO). This dataset was built upon 429 observatories with data between 1945 and 2005. It was obtained from the MOPREDAS, a dense database of monthly precipitation for Spain developed by González-Hidalgo et al. (2011), and subjected to an accurate quality control and homogeneity testing.

- EDO: the second dataset was obtained directly from the European Drought Observatory (EDO), which uses the available stations from the telecommunication net of the World Meteorological Organization. The availability of data and the density of observatories are much lower than that of the EBRO. For the Ebro Basin, the EDO dataset contains 14 observatories within the Basin or in neighbouring areas.

- CRU: the third precipitation dataset used is the CRU TS 3.1 (hereafter CRU), produced by the CRU of the University of East Anglia (UK). It has a spatial resolution of $0.5^{\circ}$.

The location of the precipitation observatories for the reference EBRO dataset, the EDO observatories and the $0.5^{\circ}$ grid CRU are showed in Figure 1 (upper map).

\subsection{Drought impact datasets}

For achieving the second objective of the study, we used two different environmental datasets:

- Tree-ring data. These data represent a proxy of annual growth data and were extracted using dendrochronological methods. The dataset corresponds to 8 mean width chronologies of Pinus halepensis Mill. forests. The forests were selected based on the dominance of $P$. halepensis in the canopy over at least 1 ha of fully forested area. At each of eight sampling sites (Figure 1, bottom map), 15-20 trees were randomly selected, separated by at least $50 \mathrm{~m}$ from each other. At least two radial cores per tree were taken at $1.3 \mathrm{~m}$ height using a Pressler increment borer. The preparation of the wood cores and the statistical standardization of the tree-ring width series were done following standard dendrochronological methods (Fritts, 1976). Further details on the dataset can be found in Pasho et al. (2011).

- Streamflow data. For the entire gauging stations network available in the Ebro Basin (López-Moreno et al., 2011), we selected different sub-basins that correspond 
to the headwaters, the medium course and the outlet of the main stream, the Ebro River. The series of monthly river discharges $\left(\mathrm{Hm}^{3}\right.$ year $\left.{ }^{-1}\right)$ were converted to standard units through calculation of the standardized streamflow index (SSI) (see the details of calculation in Vicente-Serrano et al., 2011). Figure 1 (bottom map) shows the location of the different gauging stations and their correspondent watersheds.

\section{Methods}

\subsection{Selection of a drought index}

Drought indicators are the most essential element for drought analysis and monitoring since they allow identifying and quantifying droughts (e.g., see reviews in Heim, 2002; Mishra and Singh, 2010; Sivakumar et al., 2010). For the purpose of this study, we have selected the SPI (McKee et al., 1993) since it has been recommended by the World Meteorological Organization as the reference drought index, and it only needs precipitation data to be computed.

The SPI enables to be calculated at different time scales. The time period from the arrival of water inputs to availability of a given usable resource differs considerably. Thus, the time scale over which water deficit accumulates becomes extremely important and functionally separates hydrological, environmental, agricultural and other types of drought. This multi-scalar nature of droughts (McKee et al. 1993) was the other reason for selecting the SPI versus other traditional indices (such as the Palmer drought severity index). The computation of the SPI is well documented, therefore we suggest the interested reader that check the original proposal (McKee et al. 1993), or the detailed version of the index that we have used, in Vicente-Serrano (2006) or López-Moreno and Vicente-Serrano (2008).

The SPI calculation was independent for each one of the meteorological stations from the EBRO, EDO and also for the $0.5^{\circ}$ gridded series from the CRU. Once the SPI was calculated in each station, it was spatially interpolated to obtain SPI grids for each dataset. The EBRO and EDO were interpolated at a resolution of $5 \mathrm{~km}$ to match with the drought products provided by the EDO. A method of 'splines with tension' was used to perform the interpolations (Mitasova and Mitas, 1993). We selected this method since it provides the same value of the variable in the points with available measurements (exact interpolator), which is critical in the comparison of different precipitation datasets. In addition, the method is automatic, and this was essential given the large number of monthly precipitation interpolations to be done (732 months $\times 4$ time scales). Geostatistic methods (i.e. krigging) need an assisted semivariogram fitting and they are not operative for massive interpolation. In addition, splines have provided better results than other local methods (e.g. inverse distance weighting) to interpolate precipitation data in the Ebro basin (VicenteSerrano et al., 2003), reducing the local artifacts and providing more coherent surfaces. Finally, the EBRO was re-gridded to $0.5^{\circ}$ resolution (using average of all grids within the large new grids) to be compared with the SPI obtained from the CRU dataset.

We analysed the accuracy of the interpolated maps obtained with the EBRO dataset. Although interpolating time series of climate variables is much more problematic than using average values, since the spatial variability of the climate variables increase when the cumulative period decreases (Jeffrey et al., 2001), the high spatial density of the EBRO dataset has provided very good results interpolating the time series of the SPI values. Each monthly SPI map was validated using a 'jackknifing' method, which is based on withholding one station out of the network, estimating values from the remaining observatories, and calculating the difference between the predicted and observed values for each withheld observatory (Phillips et al. 1992). We calculated the mean absolute error and the Pearson's correlation coefficient between the observed and predicted SPI values at the time scales of 3, 6, 9 and 12 months. Figure 2 shows a summary of the validation from 1945 to 2005 . The accuracy of the maps decreases when time scale increases, but the agreement between the observed and the predicted SPI values is high, with an average mean absolute error for the entire series of $0.16,0.18,0.20$ and 0.21 for the 3-, 6-, 9-, and 12 month SPI, respectively, and very high coefficients of correlation between the observed and predicted SPI values.

\subsection{Statistical analyses}

The comparison between the different datasets was performed using different statistical techniques. First, we used Pearson correlations to determine the areas of high and low agreement between datasets. We also used trend statistics to determine possible differences in the identification of the changes of drought conditions on time as a function of the dataset. Trends were calculated for each gridded point using the nonparametric Mann-Kendall (MK) test. The power of the MK test for detecting monotonic trends in time series have been previously checked (Yue et al., 2002). The test provides two useful parameters for characterizing trends: the Kendall's coefficient (tau), which indicates the sign and strength of the trend; and the statistical significance ( $p$-level) set for rejecting the null hypothesis (no trend), which in this study was $p<0.05$ (a 95\% confidence level). The computation of the test can be checked in the original proposals by Mann (1945) and Kendall (1975).

\section{Results}

5.1. Quantification of the drought severity with the different multi-scale datasets

There are important differences in the spatial detail of the drought information provided by the different dataset. As a representative example, Figure 3 shows the 3-, 6-, 9and 12 month SPI for the EBRO, EDO and CRU datasets 

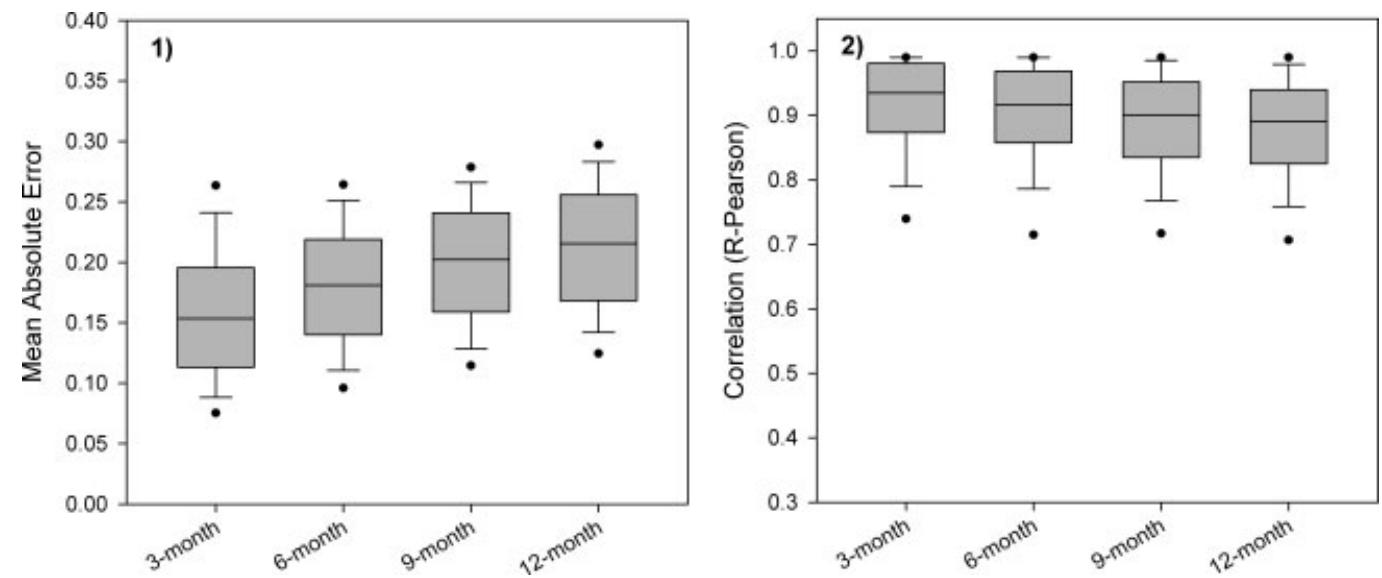

Figure 2. Box-plots summarizing the cross-validation results for the standardized precipitation index (SPI) maps of the entire time series (1945-2005): (a) Mean absolute error and (b) Coefficient of correlation ( $R$-Pearson).

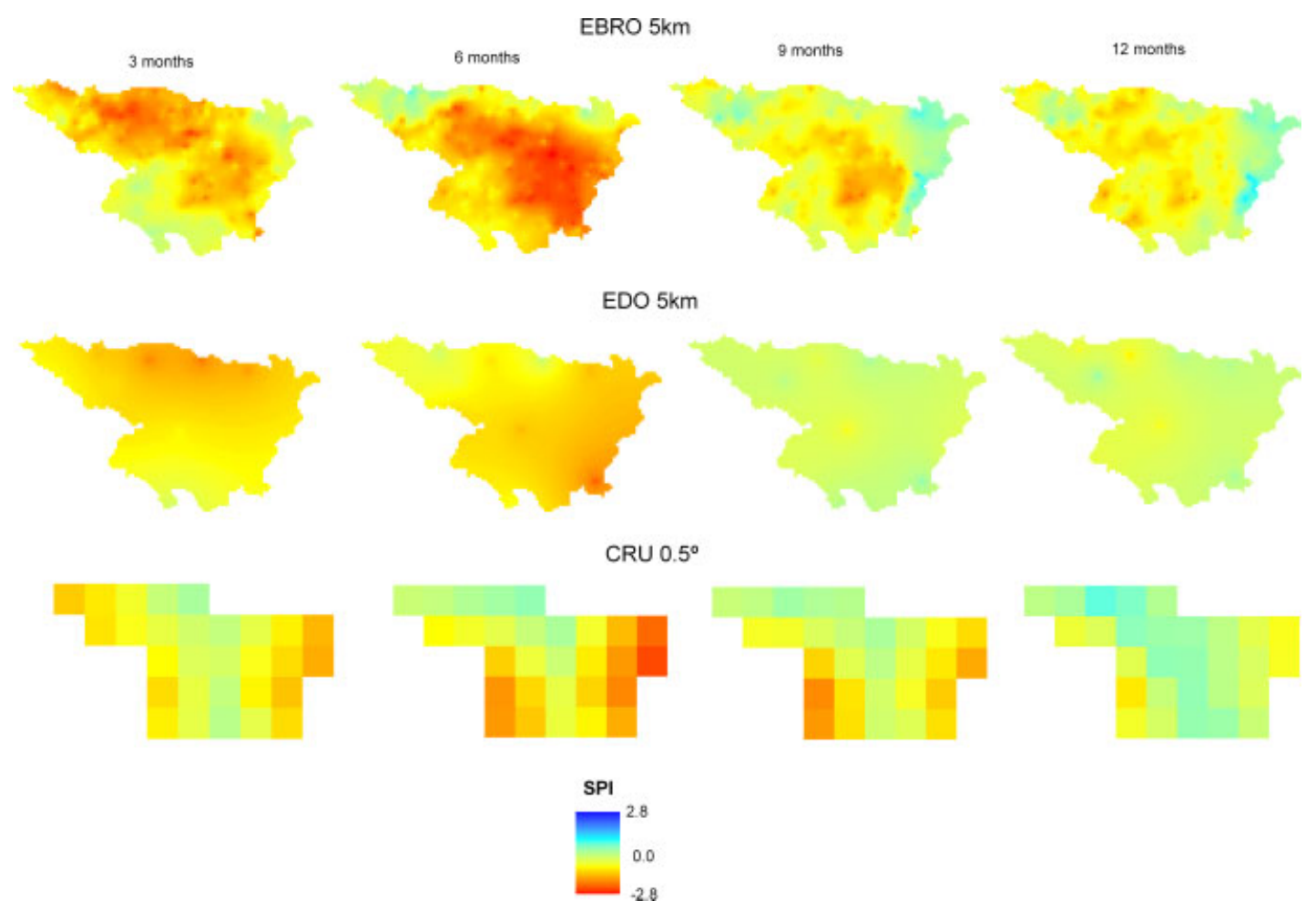

Figure 3. Example of the standardized precipitation index (SPI) datasets from the EBRO, EDO and CRU data. The maps correspond to June 1995, in which strong drought conditions affected most of the Ebro Basin.

for the Ebro Basin in June 1995, when very severe drought conditions affected most of the Basin. The EBRO dataset shows a high degree of spatial detail, recording several local features in the drought severity given the high density of precipitation observatories used. On the contrary, the EDO dataset shows more general spatial patterns in the drought conditions, with an excessive spatial filtering of the drought severity levels across the region. Finally, the CRU dataset records excessively coarse information to detect the local drought features at a regional scale.

However, as shown in Figure 4, the two 'low resolution' datasets represent quite well the general evolution of the drought conditions and the drought severity in the entire Basin. The main drought episodes recorded in the Basin from the EBRO dataset are also well identified using the EDO and the CRU datasets. At the time scale of 3 months, the correlation between the EBRO and the EDO SPI is 0.96 and between the EBRO and the CRU SPI 0.97. However, the resemblance between the different datasets decreases when the SPI time scale increases. For example, at the 12 month time scale, the magnitude of the drought episodes changes noticeably as a function of the dataset. The drought episode of 1985-1986, which showed a high magnitude from the EBRO SPI, shows much lower magnitude from the EDO SPI. In addition, the EDO dataset tends to increase the magnitude of the moist periods recorded from 1995 and to reduce the 

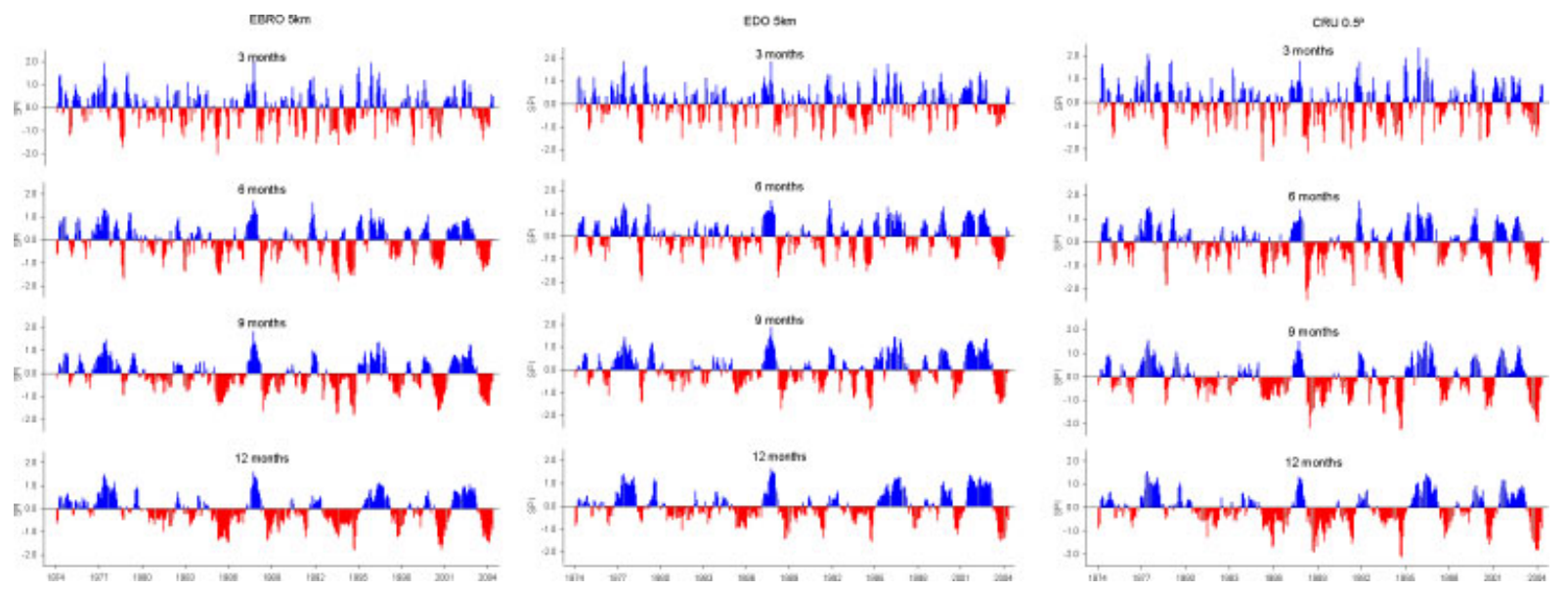

Figure 4. Average 3-, 6-, 9- and 12 month series of the standardized precipitation index (SPI) for the entire Ebro Basin based on the EBRO, EDO and CRU climatic datasets (1974-2005).

magnitude of the droughts during the same period. Disparities are as well observed between the EBRO and the CRU datasets with some differences in the magnitude and duration of the drought episodes.

Figure 5(a) shows the spatial variability in the correlation of the SPI values between datasets. As previously observed for the whole basin average time series, the correlations tend to be higher for shorter ( 3 months) than longer time scales (12 months). The lowest correlation values $(R=0.5)$ are recorded in the north-western areas, where the EDO dataset does not contain any precipitation stations; but in general correlations between datasets are higher than 0.75 in most of the Basin. Figure 5(b) shows the correlations between the EBRO SPI and the SPI from the two low resolution datasets at the time scales of 3 and 12 months for January and July. These months correspond to the coldest (January) and warmest (July) in the study area. In both months, lower correlations are found in the northwest part of the study area, mainly at the longest SPI time scales (12 months). Nevertheless, the (a)
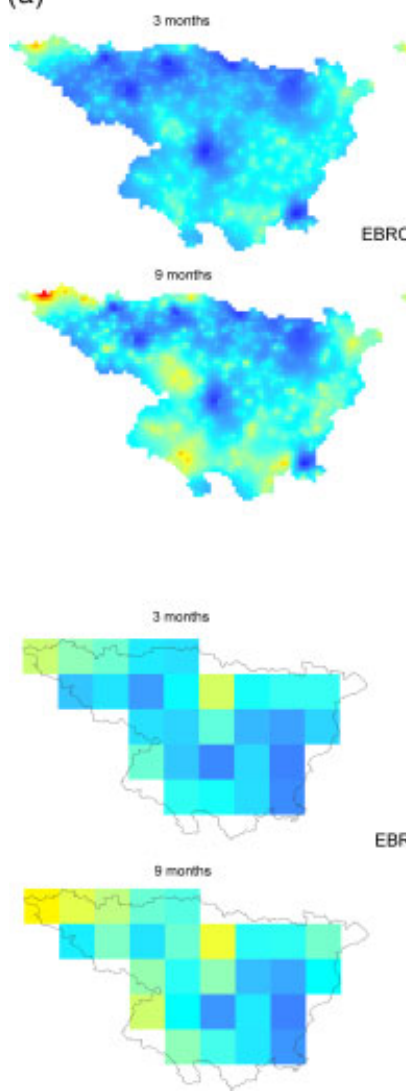

B menpes
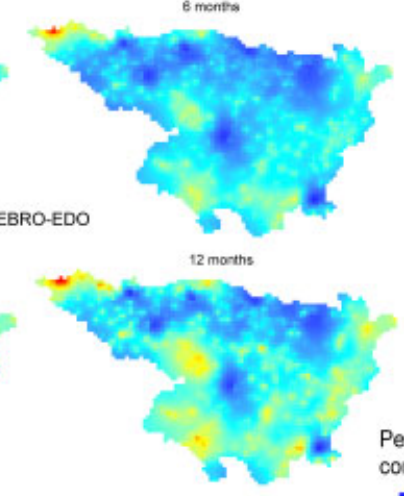

(b)

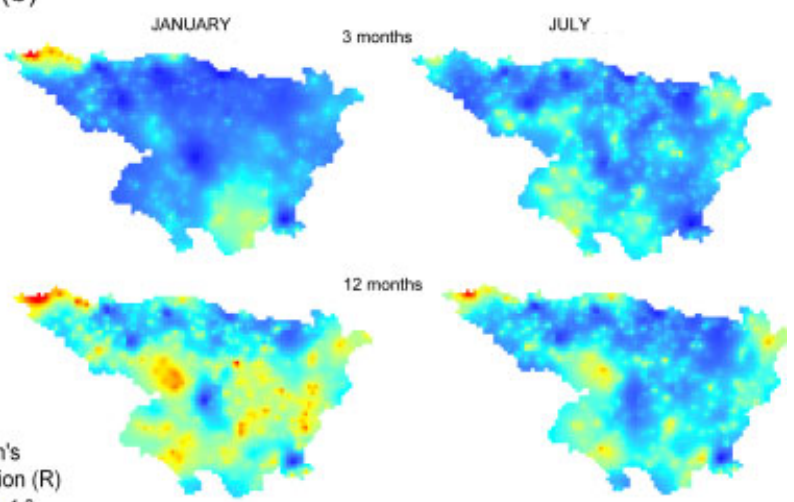

1.0
0.75
0.5
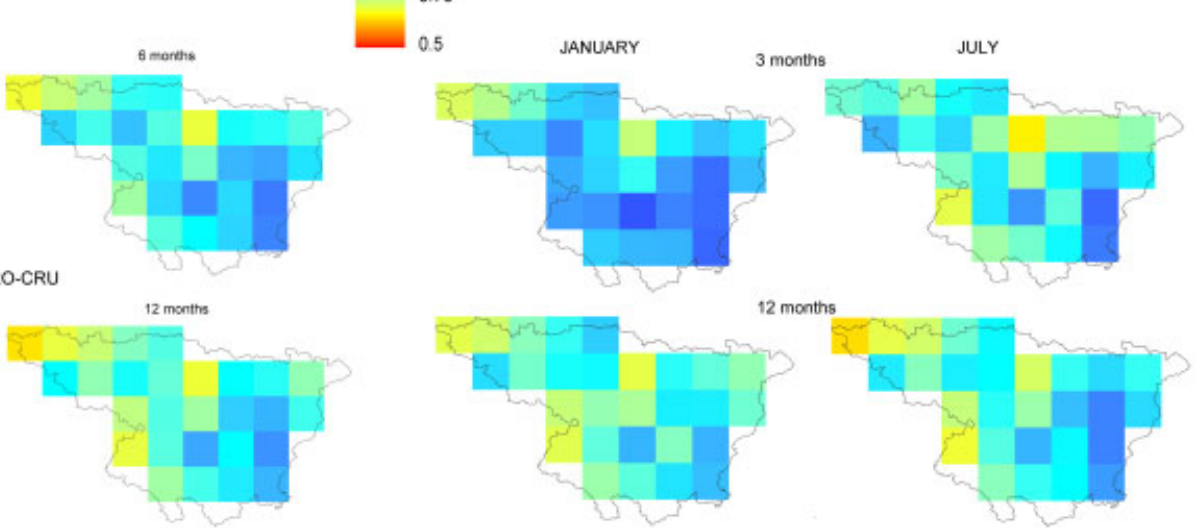

Figure 5. Correlations of SPI series between the different datasets for the period 1974-2005. (a) for the entire series, on different time scales, (b) for January and July series on 3- and 12 month time scales. 


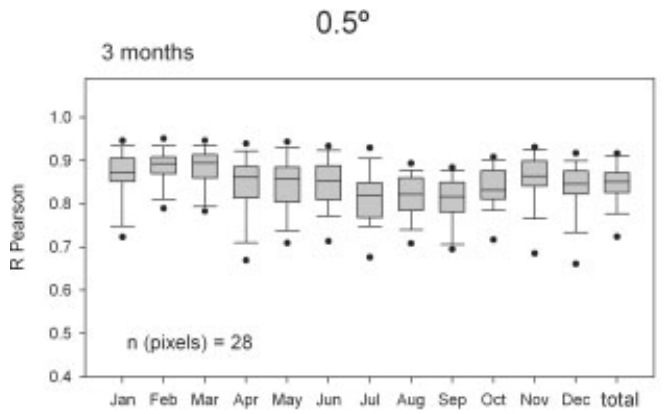

6 months

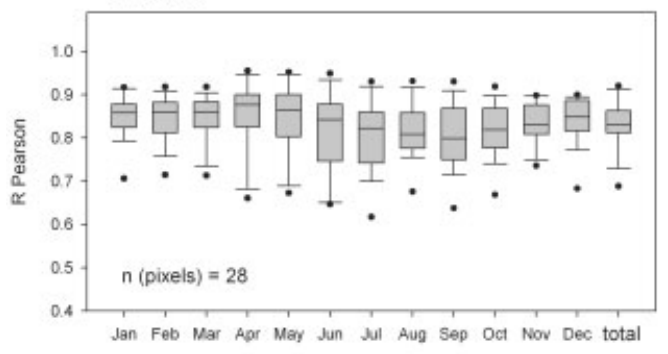

9 months

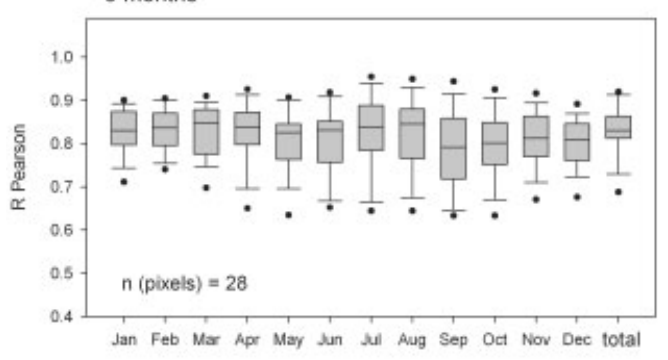

12 months

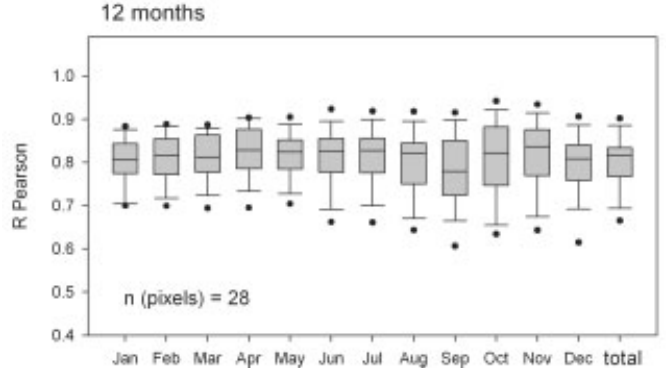

$5 \mathrm{~km}$

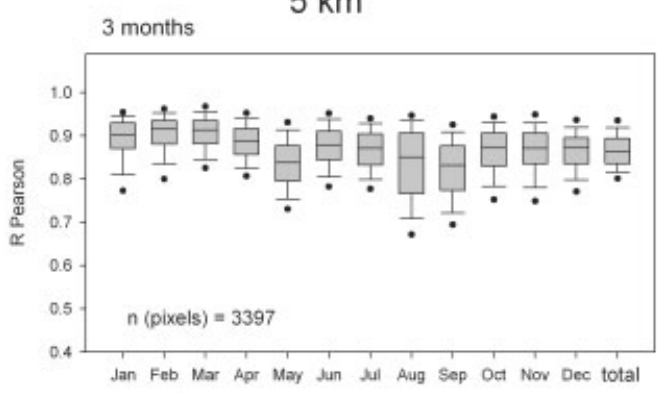

6 months

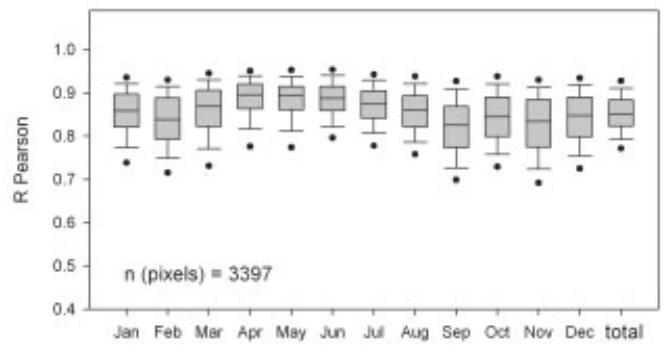

9 months

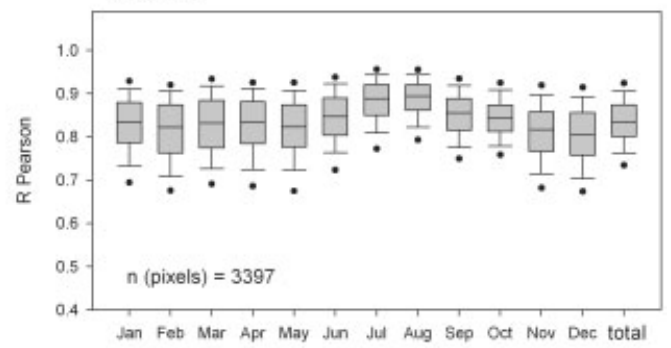

12 months

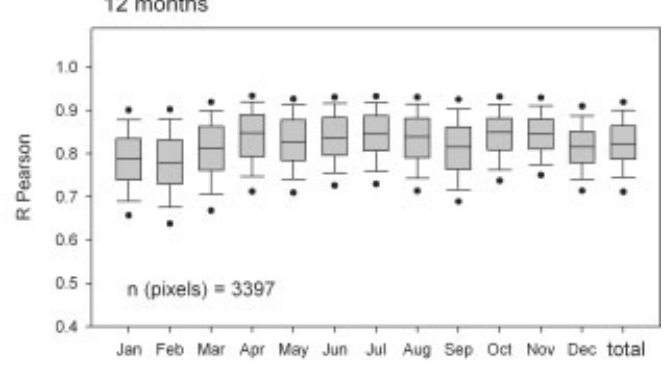

Figure 6. Box-plot of correlations between the EBRO and CRU standardized precipitation indices (SPIs) (0.5 resolution, left column) and EBRO and EDO SPIs (5 km resolution, right column) at the time scales of 3, 6, 9 and 12 months. Each bar summarizes the correlations for the complete set of $5 \mathrm{~km}$ or $0.5^{\circ}$ for the corresponding month and time scale. The plot 'total' corresponds to the correlations from the complete series without separation month by month. Box: 25 th and 75 th percentiles; whiskers: 10th and 90th percentiles; dots: 5 th and 95 th percentiles.

pattern tends to be the opposite at longer time scales, since stronger spatial variability in the correlations is found in winter than in summer. In Figure 6, the correlations for the different months of the year are summarized by means of box-plots. In general, the agreement between the EBRO SPI and the other two low resolution datasets is quite good, independently of the SPI time scale and the month of the year, as average correlations tend to be higher than 0.8 for all of the months. The aforementioned pattern of higher (lower) correlations for short (long) time scales in winter months and the opposite for summer is as well observed in Figure 7.

The evolution of the surface affected by droughts from the three datasets also provides interesting results. For this purpose, two different thresholds have been used: SPI $=-0.84$, which represents the $20 \%$ of the probability distribution of the SPI and can be considered as a threshold for moderate droughts; and SPI $=-1.65$, which is the $5 \%$ of the probability distribution and can be representative as a limit for severe droughts. Figure 7 shows the evolution of the surface affected by droughts at the time scales of 3 and 12 months considering the three datasets. Both the CRU and EDO datasets tend to record the surface area affected by droughts similarly than the EBRO dataset, independently of the SPI time scale. However, it seems that the EDO SPI tends to underestimate the surface affected by droughts at both time scales. This is probably related to the interpolation procedure, in which the SPI values are excessively smoothed in the space due to the very few observatories 

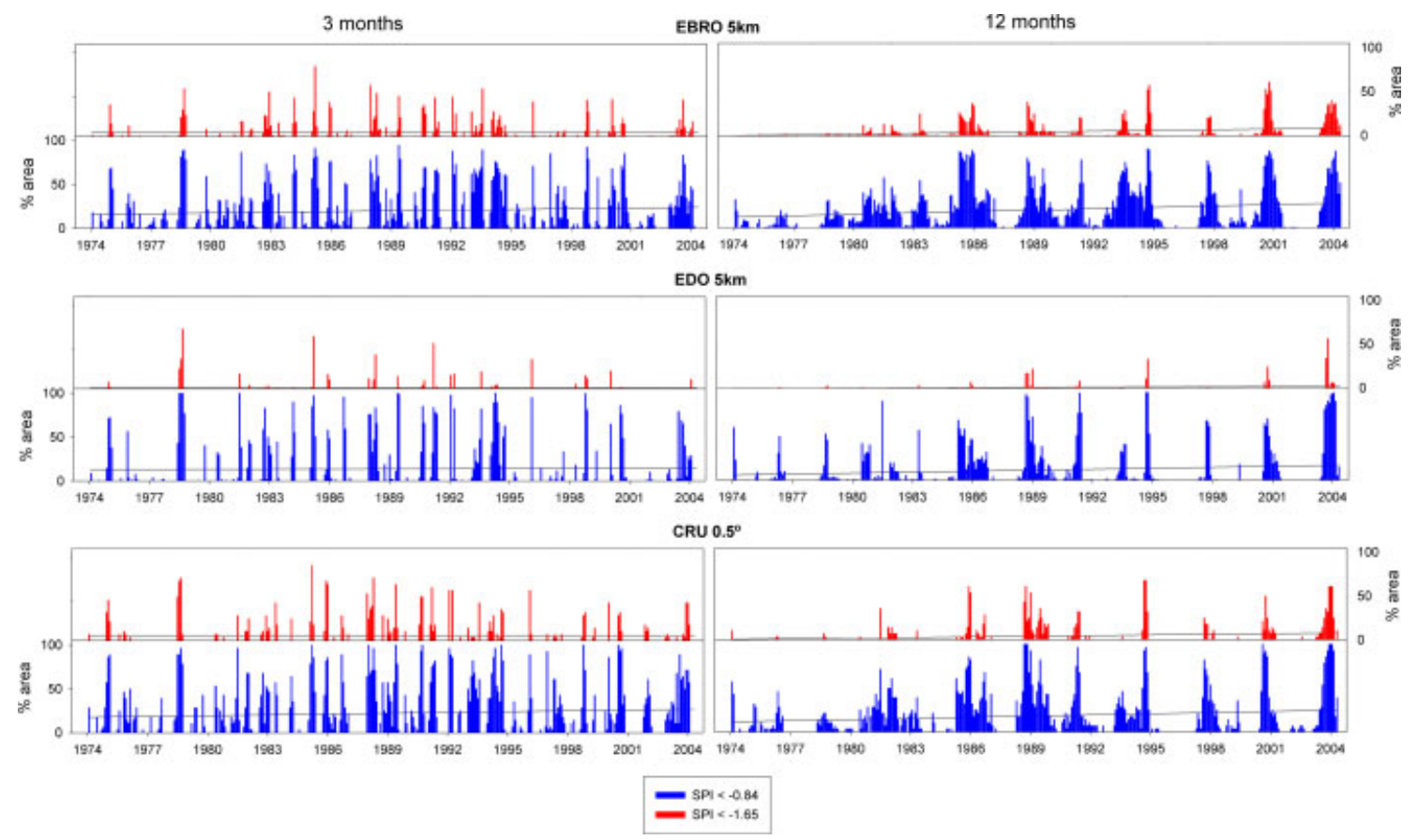

Figure 7. Evolution (1974-2005) of the surface area affected by droughts considering two SPI thresholds $(-0.84$ and -1.65$)$ at the time scales of 3 and 12 months for the EBRO, EDO and CRU datasets.

included in the EDO dataset, and the local variance is reduced compared to that recorded in the SPI maps from the EBRO dataset.

The different SPI datasets were also compared in terms of their capability of identifying the trends in the drought severity during the study period. For this purpose, we calculated the Kendall's tau statistic for the different datasets. Figure 8 shows the spatial distribution of the tau values for the time series of SPI in January and July at the 3- and 6 month time scale for the three
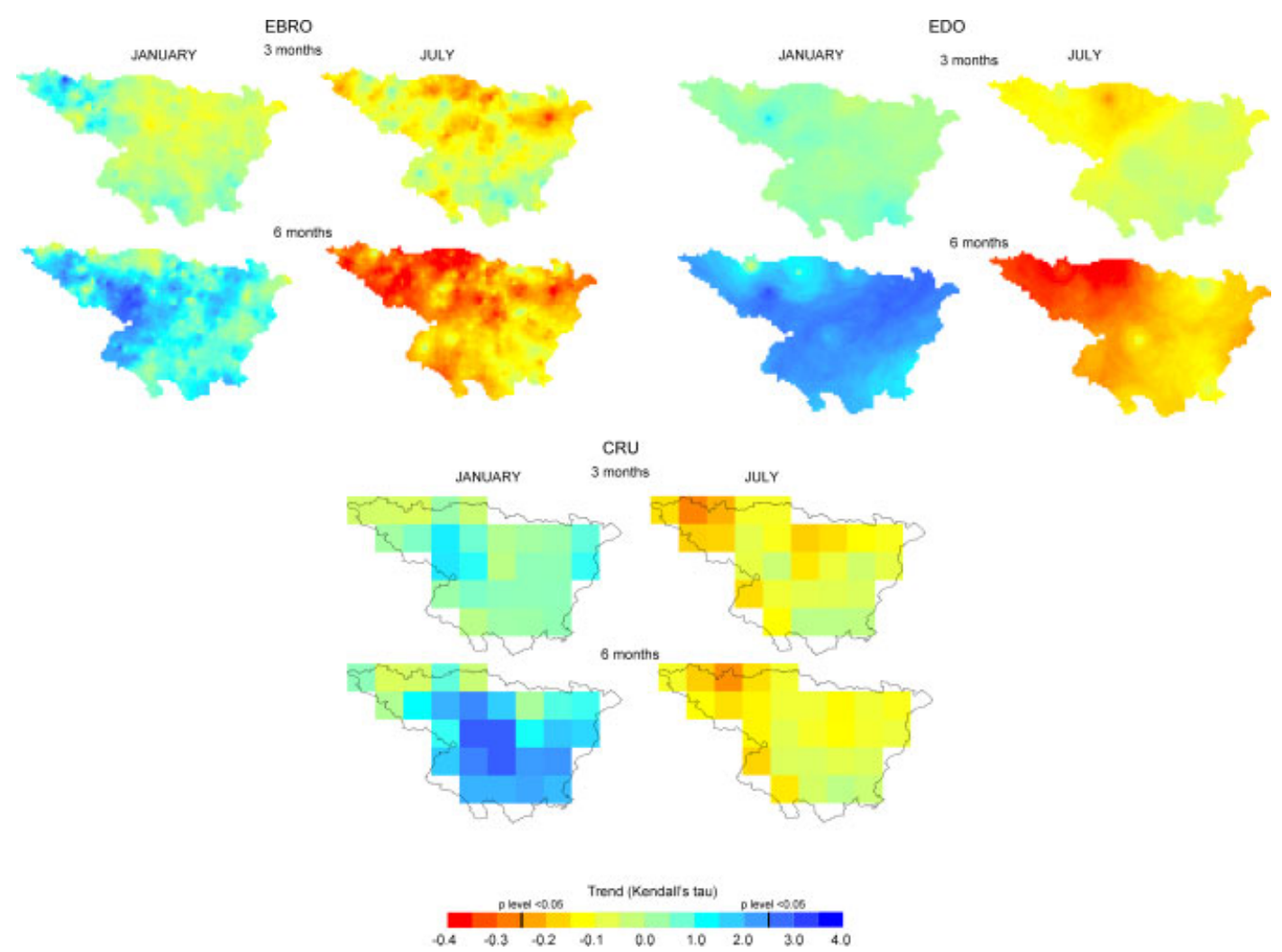

Figure 8. Kendall's tau coefficient assessing temporal trends for the 3 and 6 months January and July standardized precipitation index series, and considering the three datasets (1974-2005). 

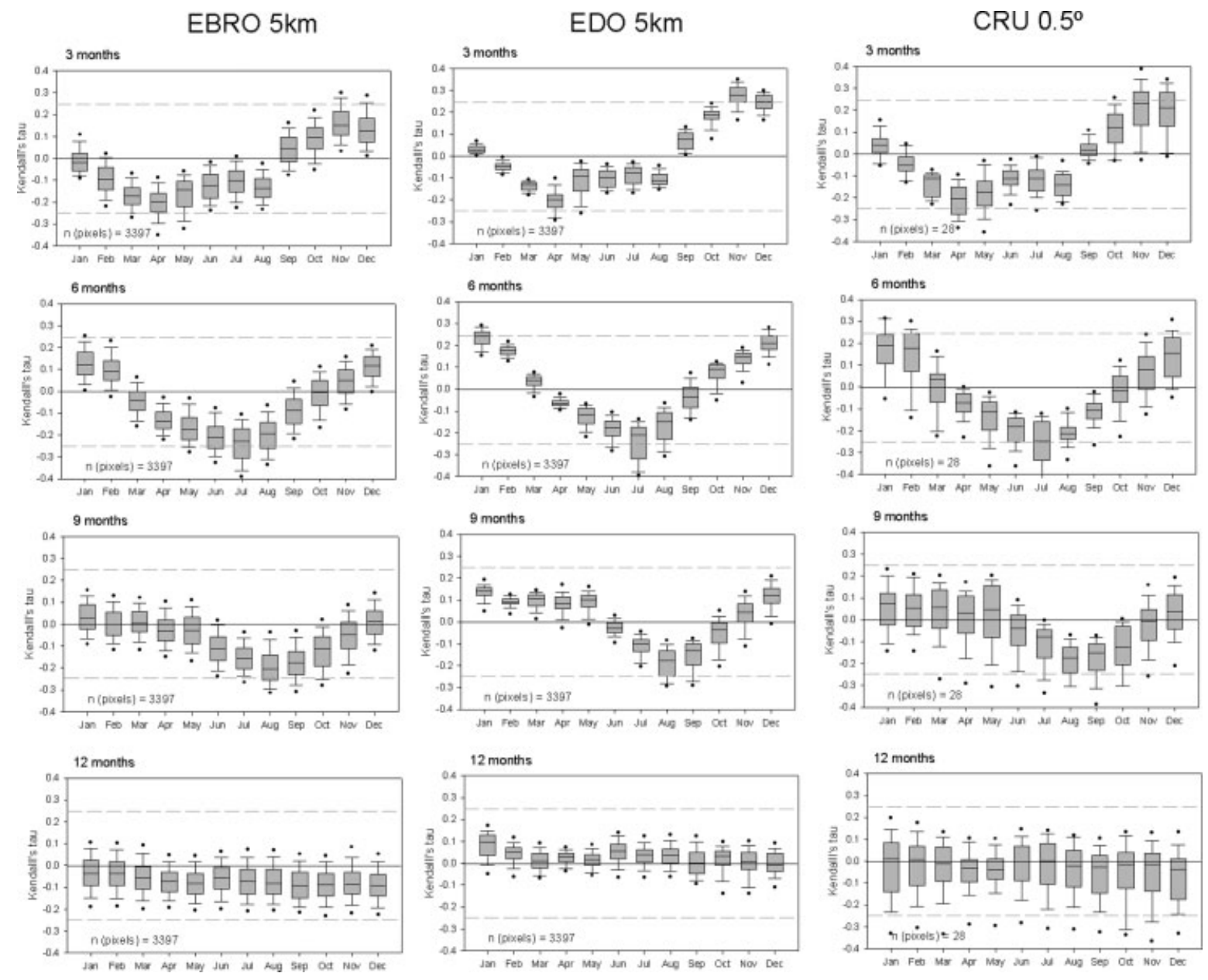

Figure 9. Box-plot of Kendall tau coefficients (trends) for the EBRO, EDO and CRU standardized precipitation indices at the time scales of 3 , 6, 9 and 12 months (1974-2005). Dashed lines indicate the threshold for statistical signification. Box: 25th and 75th percentiles; whiskers: 10th and 90th percentiles; dots: 5th and 95th percentiles.

datasets between 1974 and 2005. In January, the SPI trends are dominantly positive (more humid conditions on time) but the most important changes are identified at the time scale of 6 months, mainly in the western part of the study area. In July, the trends are dominantly negative (drier conditions) and also the 6 month time scale records the changes of higher magnitude in the Basin. These dominant positive trends in January and negative in July are also observed from the EDO and CRU datasets although large spatial differences are found. For example, the trends in January and July affect larger areas of the basin for the EDO than for the EBRO dataset, being the former less sensitive to local variability. The CRU dataset also records the positive SPI trends in January, but oppositely it does not reproduce so well the negative trends in July. Figure 9 shows a summary of the trends found for the different months and time scales from the three datasets. At the time scale of 3 months the EBRO dataset recorded negative trends between February and August, whereas positive trends were found between September and December. The same pattern is well reproduced using the CRU and EDO datasets. At the time scale of 6 month negative trends in the EBRO dataset are dominant from April to September. Although with some differences in magnitude, these are also well observed in the EDO and CRU datasets. The EDO, however, tends to produce trends of higher magnitude in some months and a lower spatial variability than the observed in the EBRO. Moreover, the CRU dataset shows a higher spatial variability in the tau coefficients. Finally, at the time scale of 12 months the EBRO dataset shows dominant negative trends for all of the months although these are mostly non-significant. On the contrary, the EDO dataset tends to show dominant low-magnitude positive tau coefficients and the CRU SPI series show a tendency to 0 values (no change), and a high spatial variability in the trend coefficients.

5.2. Capability of datasets to monitor drought impacts on tree growth

In this section, we show the different performance of the three drought datasets to identify the drought impacts on tree growth in forest ecosystems. The assessment is based on the analysis of the relationship between the annual growth of $P$. halepensis, measured by means of tree-ring width, and the series of the SPI at different time scales. The SPI series were obtained from the grid cells in which the forests are located. Since the tree-ring 

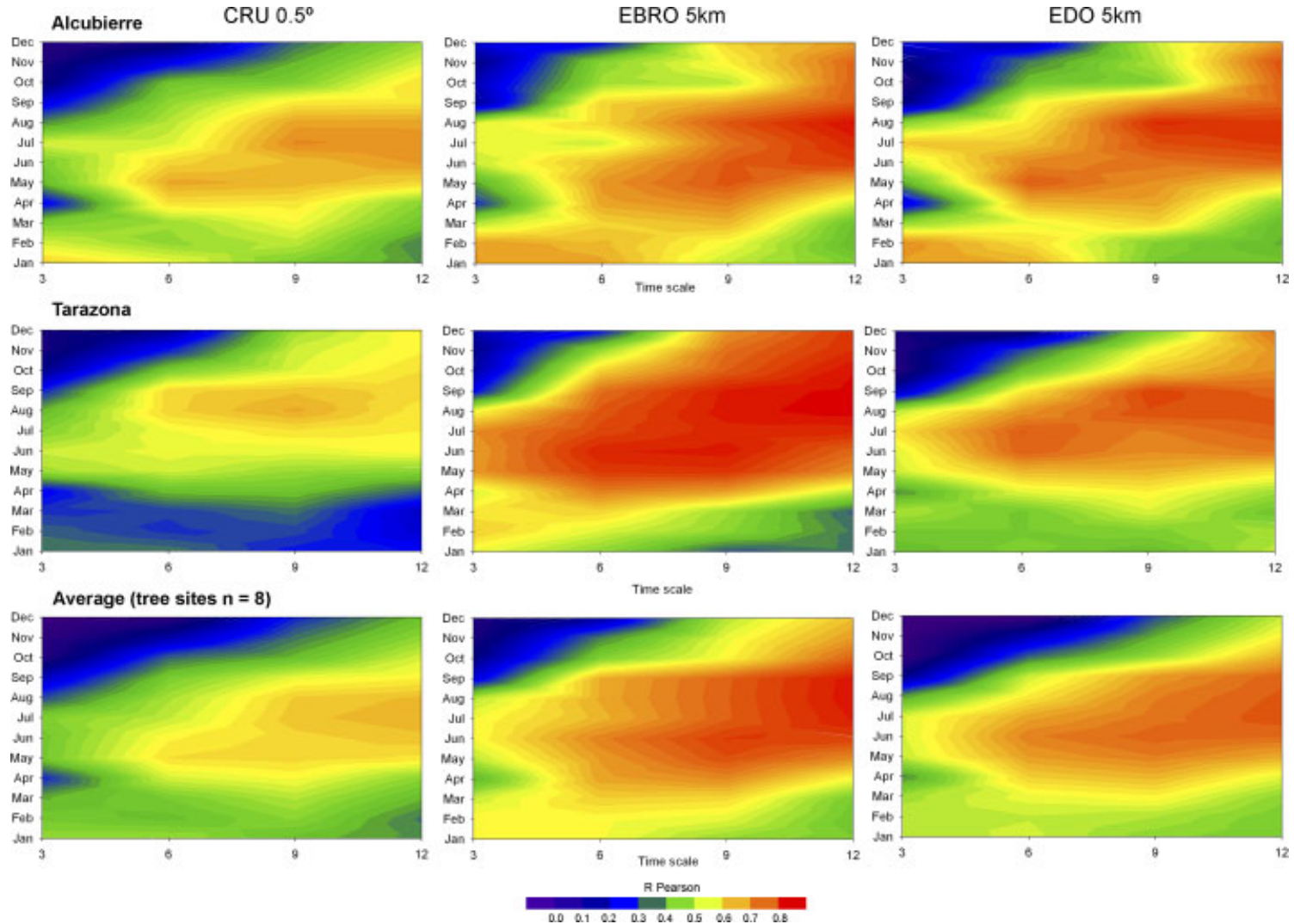

Figure 10. Correlations calculated between the monthly series of the standardized precipitation index (SPI) on time scales from 3 to 12 months and the annual tree growth of Pinus halepensis forests obtained from tree-ring width records and considering the period 1945-2005. Correlations were obtained from the EBRO, EDO and CRU SPI datasets.

width series provide annually resolved information on tree growth, correlations have been calculated between the series of annual growth and each one of the 12 monthly series of SPI. Figure 10 shows the results of the correlation analysis with examples in two forest sites and the averaged correlations for the eight-sampled forests. The contour plots reveal that the patterns of correlation in the two selected examples (Alcubierre and Tarazona) are quite similar to that observed for the average of the eight-studied forests. In general, tree growth is more determined by the drought conditions during the spring and summer months and quantified at long time scales ( $>9$ months). The results show that, as expected, the strongest correlations between the SPI and tree growth is recorded with the EBRO dataset. However, the pattern of correlations between the EDO SPI and tree growth is similar to that observed for the EBRO SPI. This is really surprising given the low spatial resolution of stations used to generate the EDO dataset. Finally, the CRU dataset provides the worst results in terms of the magnitude of correlations, albeit the pattern of months/time scale correlations is quite similar to that obtained with the EBRO dataset.

5.3. Capability of data sets to monitor drought impact on water resources

Figure 11 shows the correlation between the SPI and the series of the SSI in the selected sub-basins of the Ebro Basin. The SPI series used in this analysis correspond to the average SPI for each sub-basin, aggregated from the limits of the surface area that drain to the gauging station. The results are showed independently for the two gauging stations located in the Ebro river (the main course of the Basin) and the gauging stations of the Pyrenees (north of the Basin) and the Iberian range (south of the Basin). This separation has been done due to the different patterns of response of hydrological droughts to the various time scales of the climatic droughts. In the Pyrenees, the highest correlations between SSI and SPI are found for short time scales, and the correlation values tend to decrease when the considered time scale increases. Oppositely, in the tributaries of the Iberian Mountains, the hydrological droughts tend to respond better at longer time scales.

Correlations show that in the two stations located in the Ebro River (Zaragoza, in the middle course, and Tortosa, at the outlet) the streamflow droughts seem to be insensitive to the time scale of the climatic droughts. In both stations the EBRO SPI records higher correlations than the EDO and CRU SPI. Nevertheless, the differences are minimal between the datasets. When the correlation between the SPI and the SSI is analysed in the headwaters of the Pyrenees and the Iberian range, higher correlations are also obtained with the EBRO dataset. The differences are more important in the Iberian range as the hydrological behaviour in this zone responds more in depth to the local climatic conditions. It is clear that the low resolution EDO and CRU datasets provided slightly worse results to 

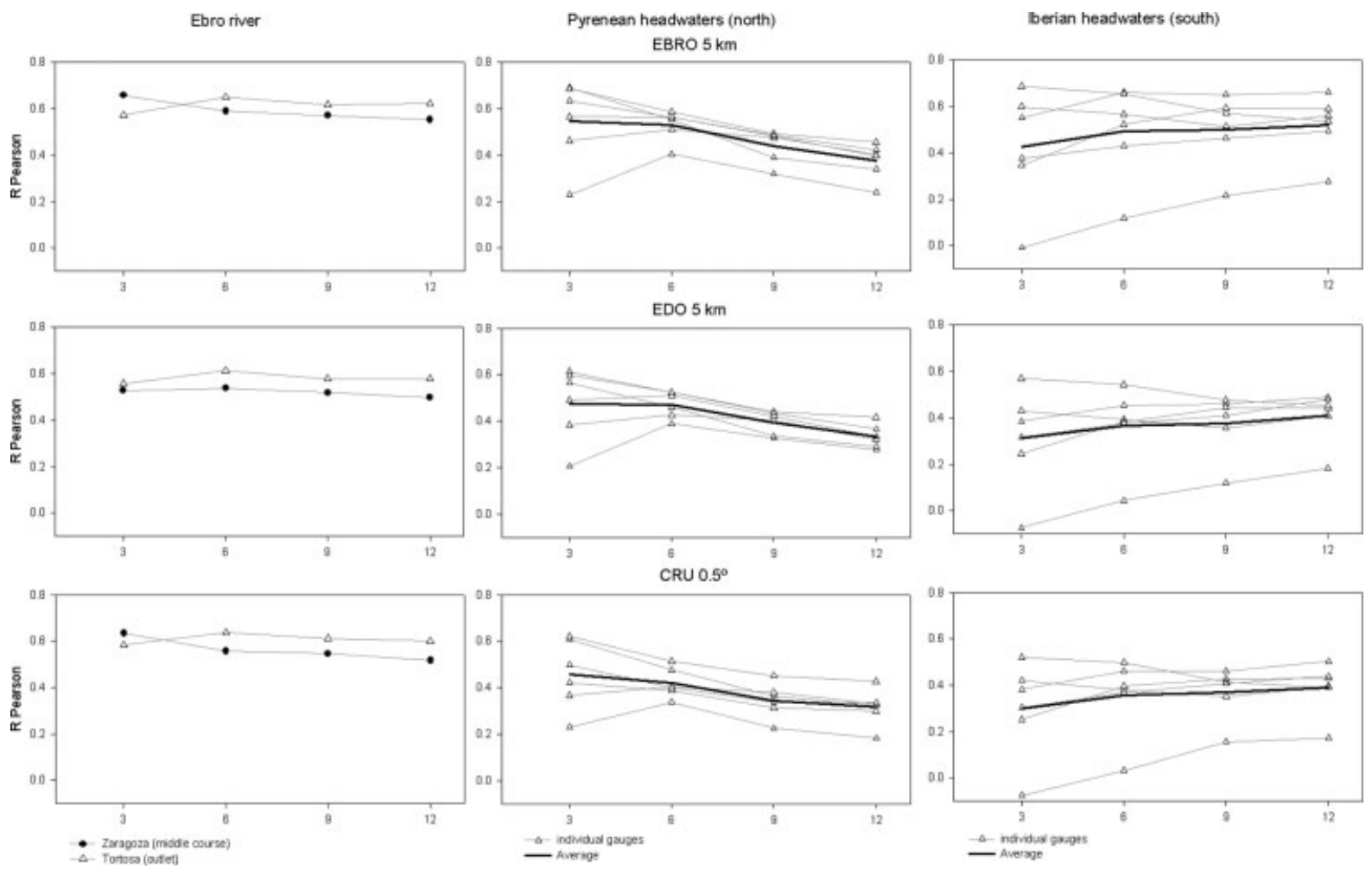

Figure 11. Correlations obtained between the series of the standardized precipitation index (SPI) at the time scales of 3, 6, 9 and 12 months and the standardized streamflow index series in different sub-basins of the Ebro Basin. Correlations were obtained from the EBRO, EDO and CRU SPI datasets.

identify drought impacts on streamflows than the EBRO dataset, but in general they reproduce well the differences in the response to different time scales of climatic droughts.

\section{Discussion and conclusions}

The above results have illustrated the capacity of the drought products, generated in the frame of European drought monitoring systems, to quantify accurately the severity of droughts, their temporal variability and trends but also to identify the drought impacts in different systems: water resources and ecology. Results show that, as expected, high resolution climate datasets allow more accurate assessment of the magnitude, intensity, duration and spatial extent of droughts than 'low resolution' datasets. In addition, given the local character of most of the drought impacts as a consequence of the variety of hydrological systems, ecosystems or land uses, fine climate datasets are preferable to identify better these impacts and to determine differences in the drought vulnerability. It must be stressed, however, that it is difficult to develop and maintain dense climate data sets, which are the base for the drought monitoring systems in Europe. Currently, most of the existing meteorological stations are not automatic and they are not able to provide real-time information to the drought monitoring systems. Given the current net of meteorological stations in Europe, it is not possible to access the data from dense networks, such as the EBRO database, since they are based on manual observations and they need careful procedures of quality control and homogenization of the data prior to be used for analyses.

One of the causes for the lack of information on real time is related to the national character of the organizations that collect and manage the climate data in Europe. Although the national nets of automatic stations are not as dense as the manual ones, they are still much denser than those provided by the World Meteorological Organization, which are subsequently used to develop the low spatial resolution climate datasets used in the different supranational monitoring systems (e.g. the EDO). At present, the meteorological agencies of various countries, such as The Netherlands (http://www.knmi.nl/klimatologie/ daggegevens/download.html) and Spain (ftp://ftpdatos. aemet.es/datos_observacion/resumenes_diarios/), are offering access to real-time information of meteorological stations. It is desirable that these initiatives extend to the rest of European countries and that a supra-national organism controls the quality of this information and homogenizes the formats. This would guarantee that all the available meteorological information can be used to supply in real time the drought monitoring systems that are being developed in Europe.

While this kind of initiatives are developed, the suitability of current available datasets for monitoring droughts must be assessed. In this work we have showed that using low spatial resolution meteorological information can be useful to quantify drought severity and to assess drought impacts. The EDO and CRU 
datasets failed mainly in detecting the spatial patterns of the specific drought episodes. This was expectable, given the high spatial variability of precipitation in the region and the low density of stations (or grids) used to build the databases. The correlation between the low resolution (EDO and CRU) datasets and the EBRO dataset tend to be lower in summer than in winter months. It is interesting to interpret these differences as a function of the diverse meteorological factors that drive the climate of the region in the different seasons of the year. In winter, the precipitation is usually related to polar depressions and associated fronts that cross the Iberian Peninsula. In summer, the Azores high is usually in its northernmost position blocking the entrance of Atlantic air masses, and most precipitation is associated to convective phenomena, thus dependent on local factors such as topography. The spatial variability of precipitation tends to be higher, therefore, in summer than in winter months. This would explain the stronger spatial differences found in the 3 month SPI for the series of July regarding January. Therefore, when short SPI time scales are used to monitor drought conditions in the Ebro Basin, the spatial density of observations is more critical in summer than in winter months. The opposite pattern was observed for long time scales, this is, lower correlation in winter than in summer months. This is because the SPI values in winter for long time scales (6-9 months) are mainly driven by the precipitation events recorded in the previous summer and autumn and the events that drive the long time scale SPI in July are recorded in winter. For example, the magnitude of the 6 month or the 9 month SPI in July will mainly depend on the winter and spring precipitation, which are less spatially variable than the summer and autumn precipitation.

In spite of the lower level of resemblance for summer months and long time scales, the correlations between datasets are rather high. This result suggests the usefulness of the two low resolution datasets for detecting both, severity and temporal variability of droughts. The results showed that the EDO and CRU databases reproduce quite accurately the temporal variability of the SPI, but the EDO fails to identify the main drought episodes affecting the region as a consequence of the excessive smoothing of the interpolated maps, especially at long time scales. Nevertheless, they allow identifying the main features of the drought changes (trends), which is of particular relevance in the frame of the current climate change scenarios, which in general project more frequent and intense droughts throughout the 21st century in southern Europe (Meehl et al, 2007; Giorgi and Lionello, 2008). Similarly to drought intensity, the EDO and CRU datasets are less sensitive to local variability in the detection of trends compared to the reference dataset.

Finally, the potential of different datasets for identifying drought impacts was examined as well. The two selected systems, water resources and forests, are critical in drought-prone regions, such as the Ebro Basin. López-Moreno et al. (2011) demonstrated a generalized decrease of streamflows in the majority of the rivers in the Basin during the second half of the 20th century, which is representative of the decrease of water resources in other Iberian basins (Morán-Tejeda et al., 2011b) and other Circum-Mediterranean areas (Kahya et al. 2004; Lespinas et al., 2010; Mavromatis and Stathis, 2011). Moreover, the projections for future availability of water resources depict a decrease of at least $20 \%$ by the end of the present century in the Mediterranean Basin (IPCC, 2007). This alerts about the necessity of large-scale information on the probable evolution of water resources in relation with drought occurrence. The studied datasets provide evidence of a high resemblance between the variability of SPI and SSI, which indicates the suitability of using real-time climatic information for preparedness and mitigation of drought consequences over the availability of water resources. However, some differences between datasets are observed in relation to the spatial scale of the studied catchments. In the stations located along the Ebro River, the differences between the three datasets for identifying drought impacts are minimal. Therefore, when the drought indices are aggregated at low spatial scales (large basins) the spatial resolution of the climatic dataset is not a limiting factor for relating streamflow and drought variability. On the contrary, when small basins located in the headwaters are analysed, the spatial resolution of the climate datasets is logically more critical since the scale is more local. When the correlation between the SPI and the SSI is analysed in the headwaters of the Pyrenees and the Iberian range, the EBRO dataset performs better than the two low resolution datasets. However, the EDO and CRU datasets are able of reproducing acceptably the patterns of change of correlation between SPI and SSI as a function of the considered time scale. Thus, in the Pyrenean headwaters the three datasets record higher correlations at low time scales and values tend to decrease with increasing time scale. On the contrary, in the Iberian headwaters, correlations are higher for long time scales, and this is as well reproduced similarly by the three datasets. The differences in the response times of streamflows to precipitation between the Pyrenees headwaters and the Iberian headwaters can be explained by natural and human-induced factors. On the one hand because of the different lithology that dominates in the two mountain ranges. While in the Pyrenees, the varied lithology induce a rapid response of the hydrological system to the climatic inputs, in the Iberian range the dominant limestones determine a higher temporal inertia in the river flows. Limestone substrates facilitate the free drain of water from precipitation straight to the aquifers, giving to a lagged response of runoff (Soulsby et al., 2010). Thus, the response of streamflows to precipitation deficits or droughts is observed for the longest temporal scales. Differing response of streamflows to precipitation due to contrasted lithology has also been observed between other Spanish mountain, the Cantabrian Range and the Central System (Morán-Tejeda et al., 2011a). On the other hand, some rivers of the Pyrenees and the Iberian mountains are regulated for irrigation, hydropower, or for managing 
floods and droughts. The different patterns of management of reservoirs may be responsible as well for the observed differences in the response times of streamflows to SPI. (Vicente-Serrano and López-Moreno, 2005; Lorenzo-Lacruz et al., 2010).

The impact of droughts on forests is of wide interest. Pasho et al. (2011) recently demonstrated the suitability of multi-scalar drought indices, such as the SPI, to monitor impacts of droughts on tree growth, given the different response of tree species or habitats to water deficit. The correlations between tree-rings width and SPI reach maximum values at the longest time scales for the $P$. halepensis indicating that tree growth is limited by the accumulated drought conditions of the previous year. At the monthly basis, the moisture conditions of spring (when the rates of radial growth are maximum; Pasho et al. 2011) and summer months are the most important in constraining the growth of trees. These two features are reproduced by the three datasets, although the EBRO reference displays the strongest correlations between treering width and SPI. At this respect, it is relevant to stress that the EDO performs notably better than the CRU dataset, which hardly reaches values of correlation of 0.6 between the tree growth and SPI series.

In general, it is observed that the drought impacts and the drought vulnerability of the different sub-systems are better identified using drought information at a high spatial resolution but the low resolution datasets also provide reliable outputs in terms of understanding multisource impacts. Further research would be desirable to assess the capability of these datasets for reproducing the vulnerability of other water-dependent systems such as those related to agriculture and tourism, given its implications for socio-economic development, especially in regions where water is a strategic resource, such as the Mediterranean Basin.

The variety of users of the real-time drought information demand the best information as is possible. At present the drought monitoring systems are not using the best available information but the current provided information is good for most of the management and scientific purposes. Therefore, the main recommendation that may be inferred from the above analyses is that drought monitoring systems must provide drought information based on the available climatic information, independently of the spatial scale at which the data is available. In addition, efforts must be conducted to improve the access to the available climatic information at real time in Europe to improve monitoring systems that allow taking more realistic decisions and more efficient drought preparedness and mitigation of the drought impacts. In this sense, the initiative of developing a Pan-EDO (Niemeyer et al., 2009; http://edo.jrc.ec.europa.eu/php/index.php?action=view \&id=201) using different spatial resolution datasets seems to be a very useful tool to access real-time information about the drought severity on different spatial levels and time scales.

\section{Acknowledgements}

This work has been supported by the research projects CGL2008-01189/BTE, CGL2011-27574-CO2-02 and CGL2011-27536 financed by the Spanish Commission of Science and Technology and FEDER, EUROGEOSS (FP7-ENV-2008-1-226487) and ACQWA (FP7-ENV2007-1-212250) financed by the VII Framework Programme of the European Commission, 'Efecto de los escenarios de cambio climático sobre la hidrología superficial y la gestión de embalses del Pirineo Aragonés' financed by 'Obra Social La Caixa' and the Aragón Government and Influencia del cambio climático en el turismo de nieve, CTTP01/10, Financed by the Comisión de Trabajo de los Pirineos.

\section{References}

Burton I, Kates RW, White G.F. 1978. The environment as hazard. Oxford University Press: New York, 240 pp.

Carbone GJ, Rhee J, Mizzell HP, Boyles R. 2008. Decision support: a regional-scale drought monitoring tool for the Carolinas. Bulletin of the American Meteorological Society 89: 20-28.

Fritts HC. 1976. Tree Rings and Climate. Academic Press: New York.

Giorgi F, Lionello P. 2008. Climate change projections for the Mediterranean region. Global and Planetary Change 63: 90-104.

Goddard L, Mason S, Zebiak SE, Ropelewski CF, Basher R, Cane MA. 2001. Current approaches to seasonal-to-interannual climate predictions. International Journal of Climatology 21: 1111-1152.

González-Hidalgo JC, Brunetti M, De Luis M. 2011. A new tool for monthly precipitation analysis in Spain: MOPREDAS database (Monthly precipitation trends December 1945-November 2005). International Journal of Climatology 31: 715-731.

Haylock M, Hofstra N, Klein-Tank A, Klok EJ, Jones P, New M. 2008. A European daily high-resolution gridded data set of surface temperature and precipitation for 1950-2006. Journal of Geophysical Research 113(D20): 119.

Heim RR. 2002. A review of twentieth-century drought indices used in the United States. Bulletin of the American Meteorological Society 83: $1149-1165$.

Herrera S, Gutiérrez JM, Ancell R, Pons MR, Frías MD, Fernández J. 2012. Development and analysis of a 50 year high-resolution daily gridded precipitation dataset over Spain (Spain02). International Journal of Climatology 32: 74-85, DOI: 10.1002/joc.2256.

Hofstra N, New M, McSweeney C. 2010. The influence of interpolation and station network density on the distributions and trends of climate variables in gridded daily data. Climate Dynamics 35(5): 842-858.

IPCC. 2007. Climate Change 2007: Synthesis Report, Pachauri RK, Reisinger A (eds). IPCC: Geneva, Switzerland, 104. pp. Contribution of Working Groups I, II and III to the Fourth Assessment Report of the Intergovernmental Panel on Climate Change.

Jeffrey SJ, Carter JO, Moodie KB, Beswick AR. 2001. Using spatial interpolation to construct a comprehensive archive of Australian climate data. Environmental Modelling \& Software 16: 309-330.

Kahya E, Kalayci S. 2004. Trend analysis of streamflow in Turkey. Journal of Hydrology 289: 128-144.

Kendall MG. 1975. Kendall Rank Correlation Methods, Griffin: London.

Lespinas F, Ludwig W, Heussner S. 2010. Impact of recent climate change on the hydrology of coastal Mediterranean rivers in Southern France. Climatic Change 99: 425-456.

López-Moreno JI, Vicente-Serrano SM. 2008. Positive and negative phases of the wintertime North Atlantic Oscillation and drought occurrence over Europe: a multi-temporal-scale approach. Journal of Climate 21: 1220-1243.

López-Moreno JI, Vicente-Serrano SM, Moran-Tejeda E，Zabalza J, Lorenzo-Lacruz J, García-Ruiz JM. 2011. Impact of climate evolution and land use changes on water yield in the ebro basin. Hydrology and Earth System Sciences 15: 311-322.

Lorenzo-Lacruz J, Vicente-Serrano SM, López-Moreno JI, Beguería S, García-Ruiz JM, Cuadrat JM. 2010. The impact of droughts and water management on various hydrological systems in the headwaters of the Tagus River (central Spain). Journal of Hydrology 386: $13-26$. 
Mann HB. 1945. Non parametric test against trend. Econometrica 13: 245-259.

Mavromatis T, Stathis D. 2011. Response of the water balance in Greece to temperature. Theoretical and Applied Climatology 104: $23-34$.

McKee TBN, Doesken J, Kleist J. 1993. The relationship of drought frequency and duration to time scales. Eight Conference on Applied Climatology. Anaheim, CA, American Meteorological Society $179-184$.

Meehl GA Stocker TF Collins WD Friedlingstein P Gaye AT Gregory JM Kitoh A Knutti R Murphy JM Noda A Raper SCB Watterson IG Weaver AJ Zhao Z-C 2007. Global climate projections. In Climate Change 2007: The Physical Science Basis Contribution of Working Group I to the Fourth Assessment Report of the Intergovernmental Panel on Climate Change. Solomon S, Qin D, Manning M, Chen Z, Marquis M, Averyt KB, Tignor M, Miller HL (eds). 2007 Cambridge University Press: Cambridge and New York.

Mishra AK, Singh VP 2010. A review of drought concepts. Journal of Hydrology 391: 202-216.

Mitasova H, Mitas L, 1993. Interpolation by regularized spline with tension. Mathematical Geology 25: 641-655.

Mitchell TD, Jones PD. 2005. An improved method of constructing a database of monthly climate observations and associated highresolution grids. International Journal of Climatology 25: 693-712.

Morán-Tejeda E, López-Moreno JI, Ceballos-Barbancho A, VicenteSerrano SM. 2011a. Evaluating Duero's basin (Spain) response to the NAO phases: spatial and seasonal variability. Hydrological Processes 25: 1313-1326, DOI: 10.1002/hyp.7907.

Morán-Tejeda E, López-Moreno JI, Ceballos-Barbancho A, VicenteSerrano SM. 2011b. River regimes and recent hydrological changes in the Duero Basin (Spain). Journal of Hydrology 404: 241-258, DOI: $10.1016 / j$.jhydrol.2011.04.034.

Niemeyer A, de Jager B, Kurnik G, Laguardia D, Magni O, Nitcheva S, Rossi C, Weissteiner. 2009. Current state of development of the European Drought Observatory Geophysical Research Abstracts Vol 11, EGU2009-12802.

Pasho E, Julio Camarero J, de Luis M, Vicente-Serrano SM. 2011. Impacts of drought at different time scales on forest growth across a wide climatic gradient in north-eastern Spain. Agricultural and Forest Meteorology 151: 1800-1811.

Perry M, Hollis D. 2005. The generation of monthly gridded datasets for a range of climatic variables over the UK. International Journal of Climatology 25(8): 1041-1054.

Phillips DL, Dolph J, Marks D. 1992. A comparison of geostatistical procedures for spatial analysis of precipitation in mountainous terrain. Agricultural and Forest Meteorology 58: 119-141.

Sivakumar MVK, Motha RP, Wilhite DA, Wood DA (eds) 2010 Agricultural Drought Indices: Proceedings of an Expert Meeting 2-4 June 2010, Murcia, Spain, 219 pp. World Meteorologica Organization, Geneva, Switzerland.
Soulsby C, Tetzlaff D, Hrachowitz M. 2010. Are transit times useful process-based tools for flow prediction and classification in ungauged basins in montane regions? Hydrological Processes 24: $1685-1696$

Svoboda M, Lecomte D, Hayes M, Heim R, Gleason K, Angel J, Rippey B, Tinker R, Palecki M, Stooksbury D, Miskus D, Stephens S. 2002. The drought monitor. Bulletin of the American Meteorological Society 83: 1181-1190.

Trenberth KE. 1997. Short-term climate variations: recent accomplishments and issues for future progress. Bulletin of the American Meteorological Society 78: 1081-1096.

Vicente-Serrano SM. 2007. Evaluating the impact of drought using remote sensing in a Mediterranean, semi-arid region. Natural Hazards 40: 173-208.

Vicente-Serrano SM. 2005. Las sequías climáticas en el valle medio del Ebro: Factores atmosféricos, evolución temporal y variabilidad espacial Consejo de Protección de la Naturaleza de Aragón. $277 \mathrm{pp}$

Vicente-Serrano SM. 2006. Differences in spatial patterns of drought on different time scales: an analysis of the Iberian Peninsula. Water Resources Management 20: 37-60.

Vicente-Serrano S López-Moreno JI. 2005. Hydrological response to different time scales of climatological drought: an evaluation of the standardized precipitation index. Hydrology and Earth System Sciences 9: 523-533.

Vicente Serrano SM, Saz MA, Cuadrat JM. 2003. Comparative analysis of interpolation methods in the middle Ebro valley (Spain): application to annual precipitation and temperature. Climate Research 24: 161-180.

Vicente-Serrano SM, Cuadrat JM. Romo A. 2006. Early prediction of crop productions using drought indices at different time scales and remote sensing data: application in the Ebro valley (North-east Spain). International Journal of Remote Sensing 27: 511-518.

Vicente-Serrano SM, López-Moreno JI, Beguería S, Lorenzo-Lacruz J, Azorin-Molina C, Morán-Tejeda E. 2011. Accurate computation of a streamflow drought index. Journal of Hydrologic Engineering 17(2): 318-332, DOI: 10.1061/(ASCE)HE.1943-5584.0000433.

Wilhite DA. 1993. Drought Assessment, Management and Planning: Theory and Case Studies. Kluwer: Boston.

Wilhite DA. 1996. A methodology for drought preparedness. Natural Hazards 13: 229-252.

Wilhite DA. 2002. Combating drought through preparedness. Natural Resources Forum 26: 275-285.

Wilhite DA, Svoboda MD. 2000. Drought early warning systems in the context of drought preparedness and mitigation. In Early Warning Systems for Drought Preparedness and Drought Management. World Meteorological Organization: Lisboa, 1-21.

Yue S, Pilon P, Cavadias G. 2002. Power of the Mann-Kendall and Spearman's rho tests for detecting monotonic trends in hydrological series. Journal of Hydrology 259: 254-271. 